\title{
Technology-assisted rehabilitation following total knee or hip replacement for people with osteoarthritis: a systematic review and meta-analysis
}

\author{
Xia Wang ${ }^{1 *}$ (D) David J. Hunter ${ }^{1,2}$, Giovana Vesentini ${ }^{1,2}$, Daniel Pozzobon ${ }^{1}$ and Manuela L. Ferreira ${ }^{1}$
}

\begin{abstract}
Background: To evaluate the effectiveness and safety of technology-assisted rehabilitation following total hip/knee replacement (THR/TKR).

Methods: Six electronic databases were searched without language or time restrictions for relevant studies: MEDLINE, EMBASE, Cochrane Library, CINAHL, SPORTDiscus, Physiotherapy Evidence Database (PEDro); from inception to November 7th, 2018. Two reviewers independently applied inclusion criteria to select eligible randomised controlled trials (RCTs) that investigated the effectiveness of technology-based interventions, compared with usual care or no intervention for people undergoing THR/TKR. Two reviewers independently extracted trial details (e.g. patients' profile, intervention, outcomes, attrition and adverse events). Study methodological quality was assessed using the PEDro scale. Quality of evidence was critically appraised using the Grading of Recommendations, Assessment, Development and Evaluation approach.

Results: We identified 21 eligible studies assessing telerehabilitation, game- or web-based therapy. There were 17 studies $(N=2188)$ in post-TKR rehabilitation and 4 studies $(N=783)$ in post-THR rehabilitation. Compared to usual care, technology-based intervention was more effective in reducing pain (mean difference (MD): $-0.25 ; 95 \%$ confidence interval (CI): $-0.48,-0.02$; moderate evidence) and improving function measured with the timed up-and-go test (MD: $-7.03 ; 95 \% \mathrm{Cl}$ : $11.18,-2.88$ ) in people undergoing TKR. No between-group differences were observed in rates of hospital readmissions or treatment-related adverse events (AEs) in those studies.

Conclusion: There is moderate-quality of evidence showed technology-assisted rehabilitation, in particular, telerehabilitation, results in a statistically significant improvement in pain; and low-quality of evidence for the improvement in functional mobility in people undergoing TKR. The effects were however too small to be clinically significant. For THR, there is very limited low-quality evidence shows no significant effects.
\end{abstract}

Keywords: Joint arthroplasty, Healthcare delivery, Telerehabilitation, Digital health, Virtual reality

\section{Background}

Knee or hip osteoarthritis are dominant sources of disability, affecting approximately 776 million people globally [1]. These conditions are leading contributors to the rapid increase in orthopaedic surgeries worldwide over the last decades, with most of the increase occurring in total knee

\footnotetext{
* Correspondence: xia.wang@sydney.edu.au

${ }^{1}$ Level 10 Kolling Institute, Institute of Bone and Joint Research, Royal North Shore Hospital, University of Sydney, Reserve Road, St. Leonards, Sydney, NSW 2065, Australia

Full list of author information is available at the end of the article
}

(TKR) and hip replacement (THR) [2]. Given the large and increasing financial burden of these procedures, potential efficiencies in the model of care for arthroplasty patients are a matter of considerable policy interest [3]. Rehabilitation services form a core component of the care pathway for THA and TKA patients, as a means of facilitating the recovery of functional independence after surgery. Due to the increased life expectancy and the limited resources devoted to public health, the demand for effective and sustainable rehabilitation services seems mandatory in order to cope with the needs of the aging population [4].

(c) The Author(s). 2019 Open Access This article is distributed under the terms of the Creative Commons Attribution 4.0 International License (http://creativecommons.org/licenses/by/4.0/), which permits unrestricted use, distribution, and reproduction in any medium, provided you give appropriate credit to the original author(s) and the source, provide a link to the Creative Commons license, and indicate if changes were made. The Creative Commons Public Domain Dedication waiver (http://creativecommons.org/publicdomain/zero/1.0/) applies to the data made available in this article, unless otherwise stated. 
Recently, innovative technologies have brought affordability and convenience to the healthcare consumers, such as eHealth, telemedicine, wearables, virtual reality (VR) and online educational tools [5]. A growing body of literature supports the use of telerehabilitation in improving patient satisfaction and health outcomes for a diverse range of clinical conditions, such as neurological diseases [6, 7], stroke [8], cancer [9], cardiac and pulmonary rehabilitation [10]. Compared to face-to-face rehabilitation, services delivered remotely via telephone or internet are more affordable and accessible, particularly for people living in rural areas [11]. In addition, telerehabilitation systems integrated with biosensors, accelerometers and educational software provide individualised support for people to monitor the progress of their physical rehabilitation at home, whilst allowing the therapist to intervene timely and effectively [12]. Several studies have shown that game-based or VR-assisted rehabilitation provides a motivating environment for achieving different therapeutic goals [13]. Importantly, these innovative technologies empower consumers to take an active role in decision-making and disease management, resulting in improvements of overall health awareness, adherence to treatment and satisfaction [14].

Despite the increasing popularity of available innovative health products in the market, there is insufficient evidence of their effectiveness or safety in musculoskeletal (MSK) rehabilitation. A few systematic reviews of telerehabilitation have been conducted but only yielded a handful of trials [15-17]. However, along with the rapid progress in the technologies and the growing service demand, the number of publications in this topic also increased since then, thus, it is necessary to update the evidence at a timely manner. In addition, other blooming technologies, such as game therapy and virtual biofeedback have not been well investigated. Thus, this review aimed to update the current evidence and evaluate the effectiveness and safety of technology-based rehabilitation in comparison with usual care in people undergoing TKR and THR.

\section{Methods}

A protocol for this review was registered a priori in PROSPERO (CRD42017078924) and preliminary results were presented in a conference [18]. This systematic review with meta-analyses reported according to the Preferred Reporting Items for Systematic Reviews and Meta-Analysis (PRISMA) statement [19]. All the screening, data extraction and quality assessment were performed by two authors (XW, GV) independently and any disagreement was resolved by consensus with a third reviewer (MLF).

\section{Literature search}

Six electronic databases were searched without language or time restrictions for relevant studies: MEDLINE, EMBASE, Cochrane Library, CINAHL, SPORTDiscus, Physiotherapy Evidence Database (PEDro); from inception to November 7th, 2018. The search strategy was developed by a research librarian and contained both controlled vocabulary and free text terms (Additional file 1: Appendix 1). The initial search strategies included lumbar spinal surgeries, as lumbar spinal surgeries are also highly prevalent in orthopaedic surgeries. However, there is only one study in lumbar spinal surgeries has been identified, so we only reported results for TKR and THR in this paper.

\section{Study selection}

The population of interest was people undergoing rehabilitation after elective TKR and THR. Eligible studies were randomised controlled trials (RCTs) that investigated the effectiveness of any technology-based intervention, in isolation or in combination with other interventions, compared with usual care and no treatment. Technology-based interventions were defined as any type of health-related services such as education, monitoring or treatment delivering via telecommunication technologies, internet, software or VR devices. The primary outcomes were pain and function. The secondary outcomes were quality of life, adherence, user experience and safety.

\section{Data extraction}

Trial details, including patients' clinical profile, intervention, outcomes, attrition and adverse events (AEs), were recorded on a dedicated trial description form. Outcome data included mean score, mean difference (MD) between groups, odds ratios (ORs), risk ratios (RRs), standard deviations (SDs) and standard errors (SEs). Outcome data were extracted for short-term (immediate effect post-intervention to $\leq 3$ months follow up), mediumterm (3 to 6 months follow up) and long-term ( $\geq 6$ months follow up) assessments. When more than one follow-ups were performed within each category, data from the shortest period of follow up were extracted.

\section{Study methodological quality}

The PEDro scale [20] was used to determine the methodological quality of each study. This 10-point scale is a valid assessment tool for the internal and external validity of randomised clinical trials, with acceptable reliability: intraclass correlation coefficient (ICCs) for interrater reliability of 0.56 for the total score; and 0.68 for consensus ratings $[21,22]$. When available, quality scores were extracted from the PEDro database (www. pedro.org.au). Studies with a score of 7 or greater were considered "high quality" [23]. 


\section{Quality of evidence}

The Grading of Recommendations, Assessment, Development and Evaluation (GRADE) approach was used to appraise the quality of evidence for making clinical practice recommendations [24]. The quality of evidence was initially considered as high and downgraded based on five criteria: high risk of bias (e.g. $>25 \%$ of participants for studies with a PEDro score of $\leq 6)$, inconsistency of results $\left(\mathrm{I}^{2}>50 \%\right)$, indirectness (comparison of different populations and interventions), imprecision (e.g. sample size $<400,95 \%$ CI overlaps no effect) and publication bias (visual inspection of funnel plots and Egger's regression test) [24].

\section{Data synthesis and analysis}

For the meta-analyses, whenever possible, outcomes were converted to a standard scale. For all variables with the same outcome, MDs or standardised MDs (SMD) with a
95\% CI were calculated. Trials deemed clinically homogeneous were grouped according to 1) outcome measure, 2) follow-up duration and 3) surgery type. Between-trial heterogeneity was evaluated by visual inspection of the forest plots [25] and the $\mathrm{I}^{2}$ statistic $\left(\mathrm{I}^{2}<50 \%\right.$ : low to moderate; $\mathrm{I}^{2}$ $\geq 50 \%$ : substantial; $\mathrm{I}^{2}>75 \%$ considerable heterogeneity) [26]. Random effect models were used to pool study results with considerable heterogeneity (i.e. $\mathrm{I}^{2}>75 \%$ ) [26]. Meta-analyses were performed using Review Manager, Version 5.3.

\section{Results}

\section{Results of the search}

In total, 21 RCTs (from 20 publications, $N=2971$, mean age $=65.2$ years old) were included after the screening of 8603 relevant studies retrieved from various databases. Figure 1 shows the PRISMA flowchart for the screening.

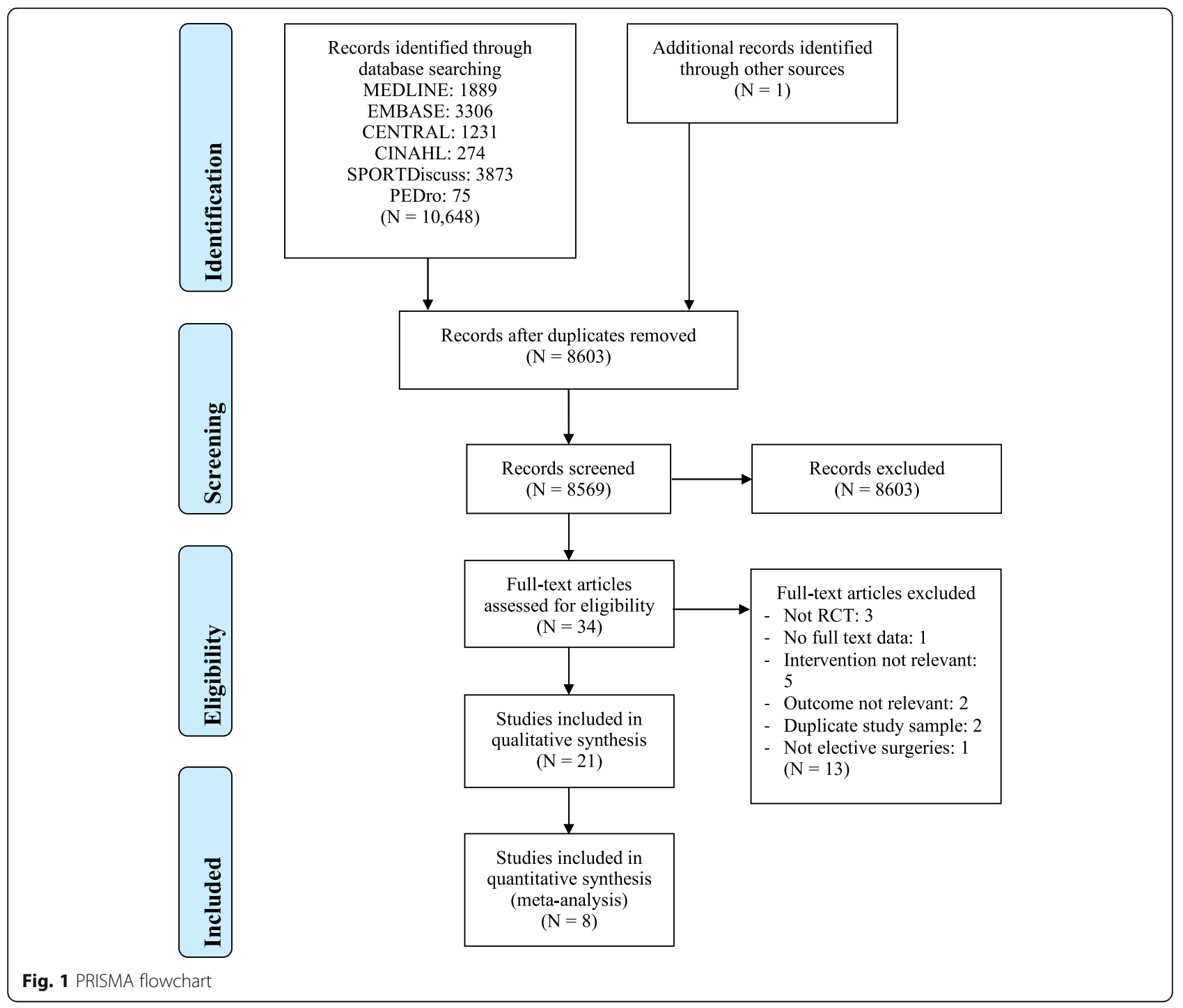


The characteristics of included participants, interventions, outcomes and main findings are detailed in Table 1.

The average methodological quality of included studies was 5.8 (range: 2 to 8 ) on the PEDro scale (Table 1). A total of 7 studies $(N=1494$, mean age $=65.8$ years old $)$ [27-33] were considered of high methodological quality (PEDro score $\geq 7$ ). The most common methodological limitation was lack of blinding of the assessor observed in 10 of the 21 included trials $(N=1364)$; or therapist (16 trials, $N=1817$ ).

\section{Details of included studies Type of technologies}

A total of 11 RCTs $(N=1596)$ investigated telerehabilitation via telephone counselling/coaching (6 trials, $N=$ 1070 ) or video-conferencing ( 5 trials, $N=526$ ). Nine RCTs $(N=1120,69.7 \%$ of all participants, mean age $=67.6$ years old) included people having post-TKR rehabilitation [27, $30-37$ ] and 2 RCTs $(N=234$, mean age $=69.2$ years old $)$ included people undergoing post-THR rehabilitation [29, 38]. There is one study in TKR that used an additional accelerometer and gyroscopes to track patient's body movement as part of the videoconference system [37].

Game-based therapy using video games, VR or biofeedback technologies was investigated in 5 trials $(N=$ 232 , mean age $=64$ years old) of post-TKR rehabilitation (Table 1) [28, 39-42]. In 2 studies, participants used the Wii balance board for weight-bearing and balance exercise training $[28,40]$. In another study, participants were equipped with two Wii game consoles on their legs to perform knee flexion or extension exercises [39]. One trial developed a 3-D avatar in an automatic virtual environment while using a robot-assisted walking device that simulated a normal walking process in a partial weight support condition [41]. In another recent study, participants were asked to row a boat using interactive VR with robotic-assisted passive knee range of motion (ROM) exercises [42].

There were 5 eligible studies $(N=1143)$ using webbased therapies, including educational software and interactive online platform, for participants following TKR $(N=594$, mean age $=65.4$ years $)$ or $\mathrm{THR}(N=549$, mean age $=62.2$ years $)$. Three studies provide multimedia online training platform used by therapists for 149 TKR and 149 THR participants, respectively [43]. Two studies use asynchronous educational software designed for handheld devices for 29 TKR participants [44].

\section{Efficacy outcomes}

Pain Our pooled analysis of 5 studies $(N=504)$ [27, 32, $37,42,44]$ showed that technology-assisted rehabilitation significantly improved pain measured on an 0-10point visual analogue scale (VAS), compared to usual care, for people undergoing TKR (MD: -0.25; 95\% CI: $0.48,-0.02)$ at 3 months follow up. Particularly, the subgroup analysis of telerehabilitation showed a statistically significant pain improvement (MD: -0.19 ; 95\% CI: $0.36,-0.03)$ comparing with controls. However, both the effect sizes were too small to be of clinical significance (Fig. 2). There was no heterogeneity between the trials in telerehabilitation subgroup $\left(P=0.44 ; \mathrm{I}^{2}=0 \%\right)$. The quality of evidence is "moderate" due to serious risk of bias (Table 2). Due to the insufficient studies in each meta-analysis (<10 studies), publication bias was not assessed.

\section{Function Time up and Go test (TUGT)}

Our analyses pooling 2 studies $(N=207)$ [32, 37] showed that telerehabilitation significantly improved function, assessed via the TUGT (measured by second; less time spend indicates better function) [45] over a short term ( 2 weeks to 3 months), compared with usual rehabilitation for people following TKR (MD: -7.03; 95\% CI: $11.18,-2.88)$. There was a substantial heterogeneity $(P=$ $\left.0.11 ; \mathrm{I}^{2}=60 \%\right)$. No difference was observed for those undergoing THR (MD: -0.70; 95\% CI: - 1.47, 0.07) (Fig. 3). The quality of evidence was considered as "very low" because of the serious risk of bias, inconsistency and imprecision (Table 2).

\section{6 minute walking test $(6 \mathrm{MWT})$}

There were two RCTs $(N=258)$ [31, 41] assessed mobility via $6 \mathrm{MWT}$ (measured by metre; longer distance indicates better mobility) [46] showing technology-assisted rehabilitation is not significantly superior to usual care in people who underwent TKR (MD: 29.36; 95\% CI: $6.99,65.71)$ at the short-term (2 to 3 months) (Fig. 4$)$. A high heterogeneity was detected $\left(P<0.01 ; \mathrm{I}^{2}=88 \%\right)$. The quality of evidence was downgraded to "very low" due to serious risk of bias, inconsistent results between 2 studies and indirectness of interventions (i.e. telerehabilitation and robotic-assisted VR were analysed together) (Table 2).

Western Ontario and McMaster Universities Osteoarthritis Index (WOMAC)

Four trials reported change in WOMAC on a 5-point Likert scale (standardised to 0-4 for each subscale) [47] $(N=746)[27,30,32,33], 3$ trials reported pain $(N=560)$ $[30,32,33]$ and stiffness $(N=371)$ subscales [27, 32, 33]. There is low-to-moderate quality, downgraded for serious inconsistency and imprecision (data not shown), that telerehabilitation is not superior to usual care in improving WOMAC pain (MD: -0.09; 95\% CI: - 0.22, 0.04; $\mathrm{I}^{2}=15 \%$; moderate evidence), function (MD: -0.05 ; $95 \%$ CI: $-0.16,0.06 ; \mathrm{I}^{2}=34 \%$; moderate evidence) or stiffness (MD: $-0.07 ; 95 \% \mathrm{CI}:-0.32,0.17 ; \mathrm{I}^{2}=67 \%$; very low evidence) at the 3 months follow-up (Additional file 2: Fig. $\mathrm{S} 1, \mathrm{~S} 2$ and S3). 


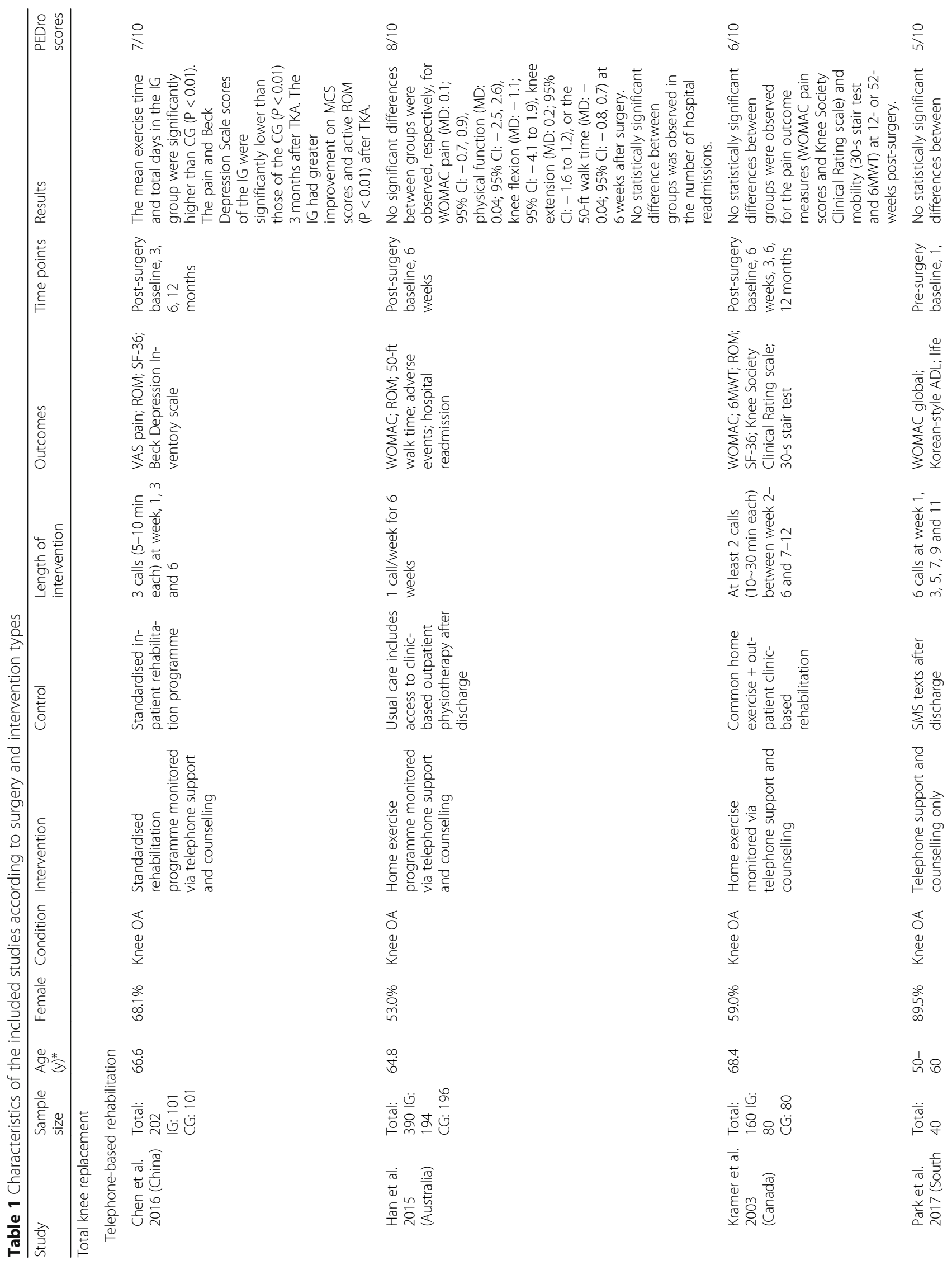




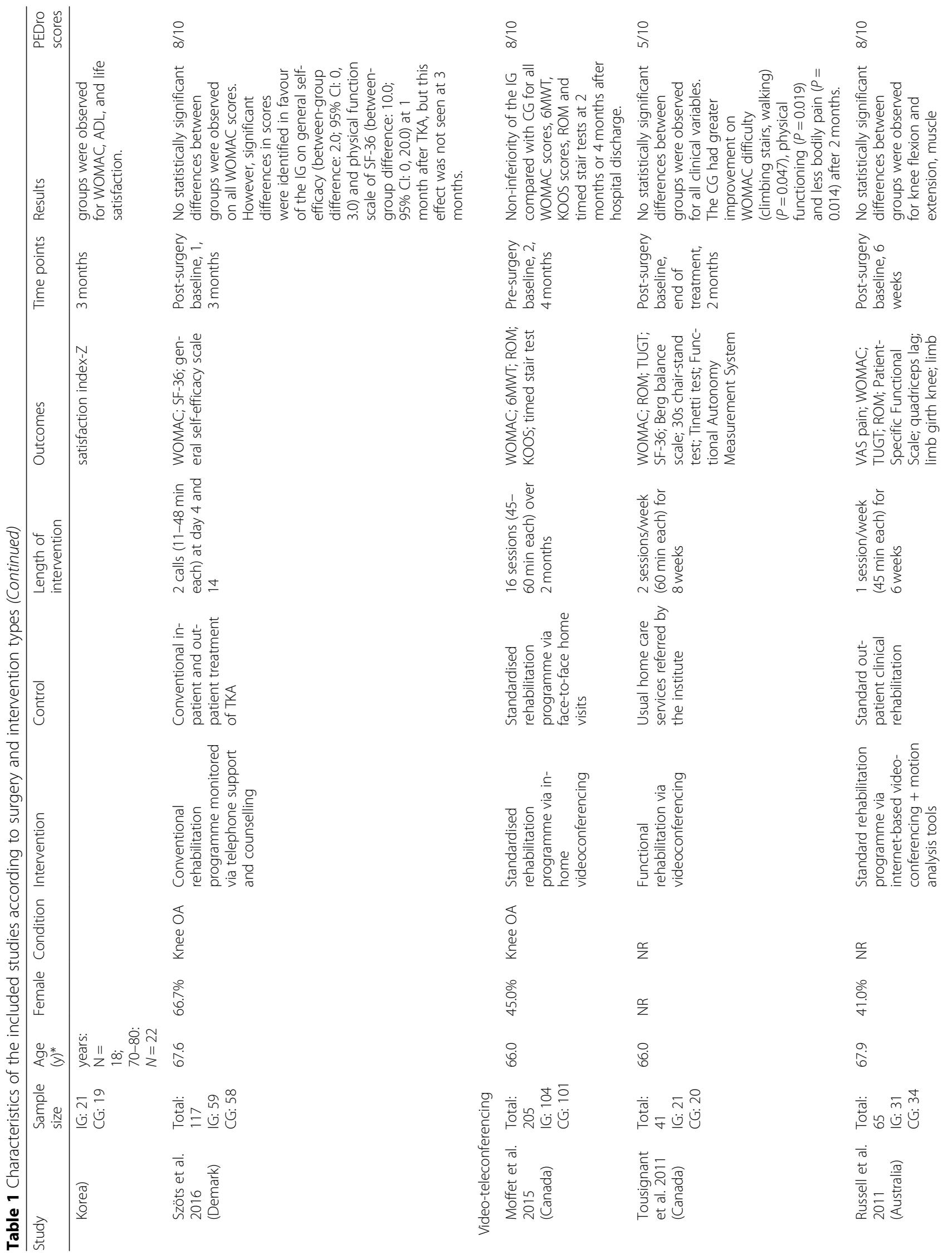




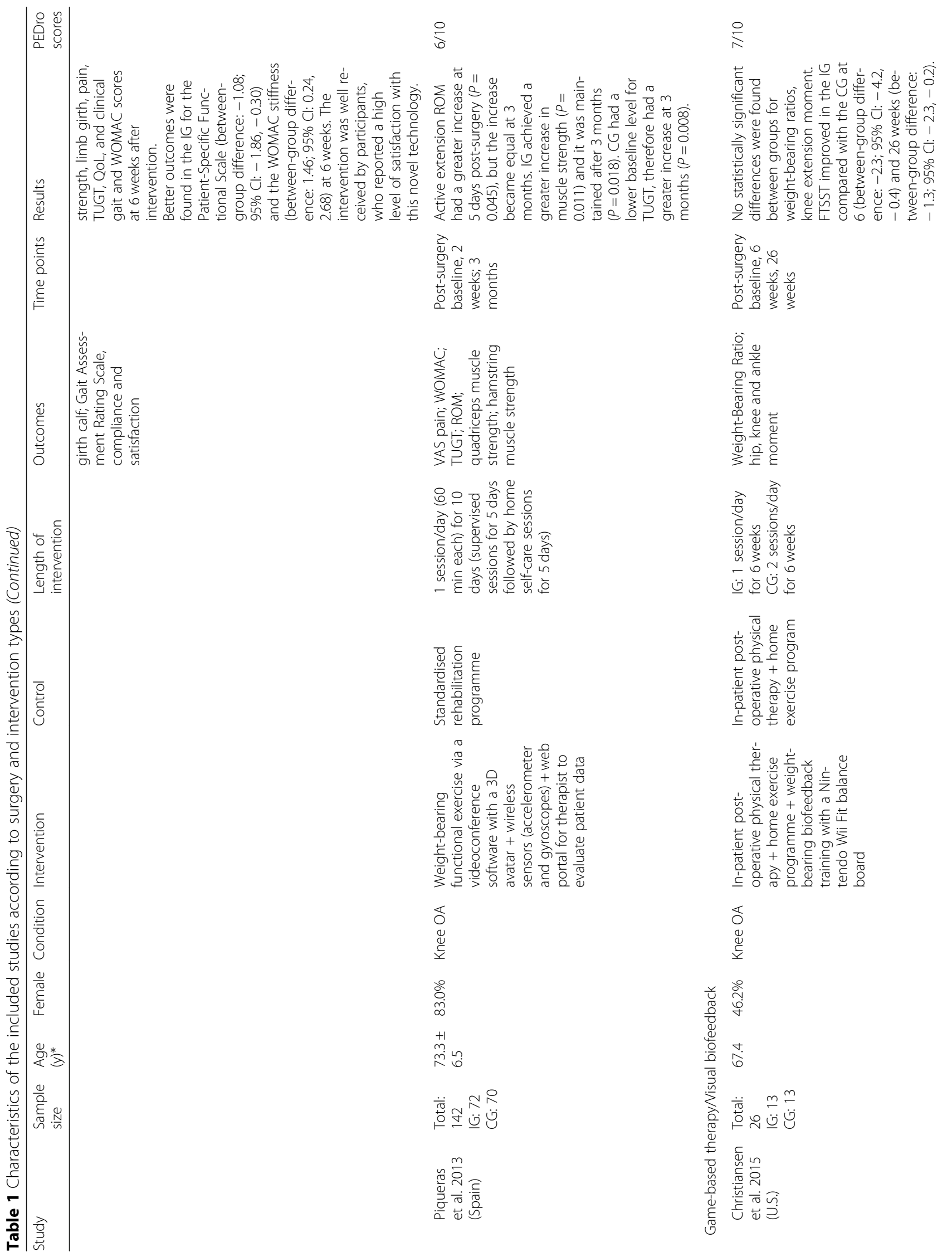




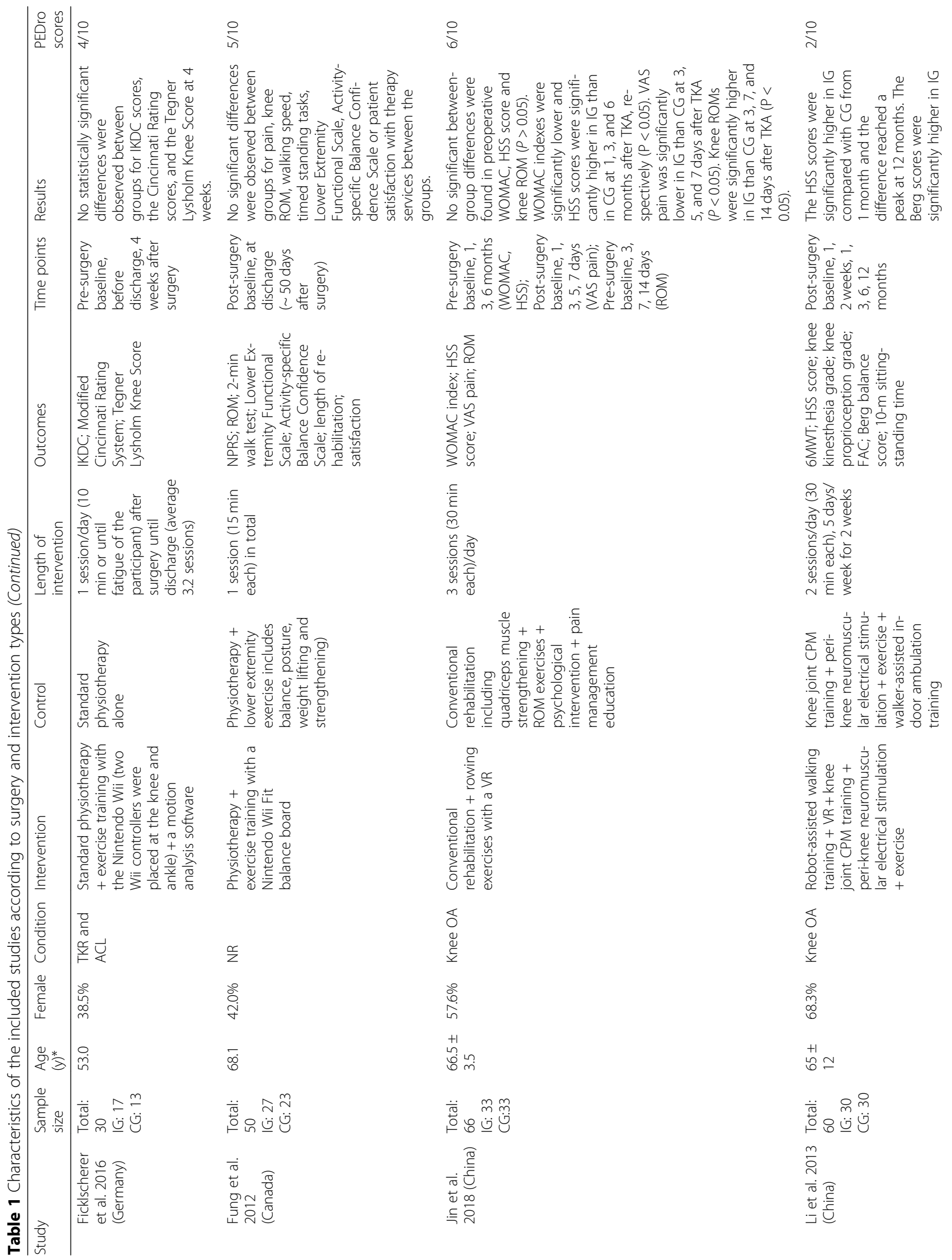




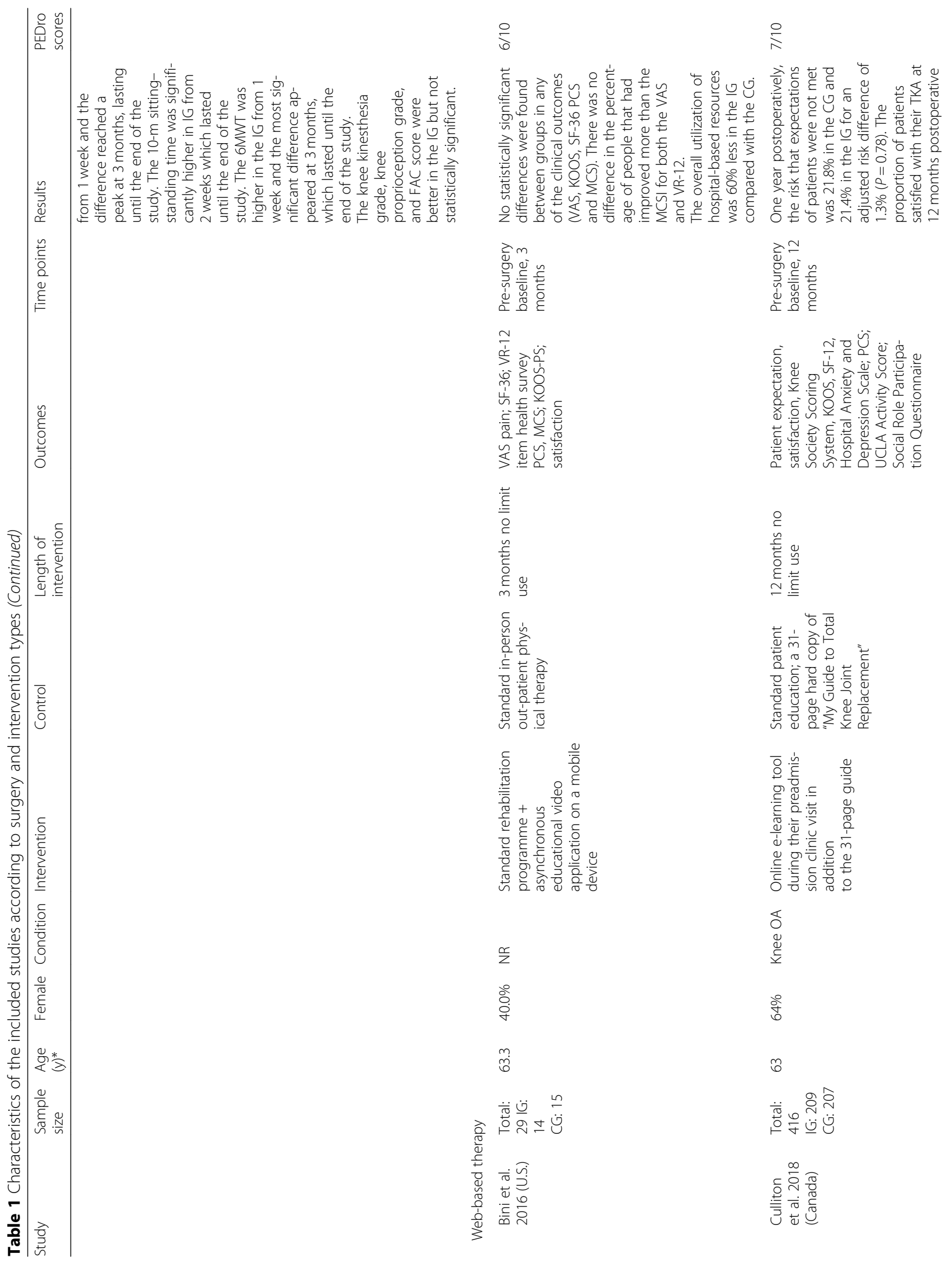




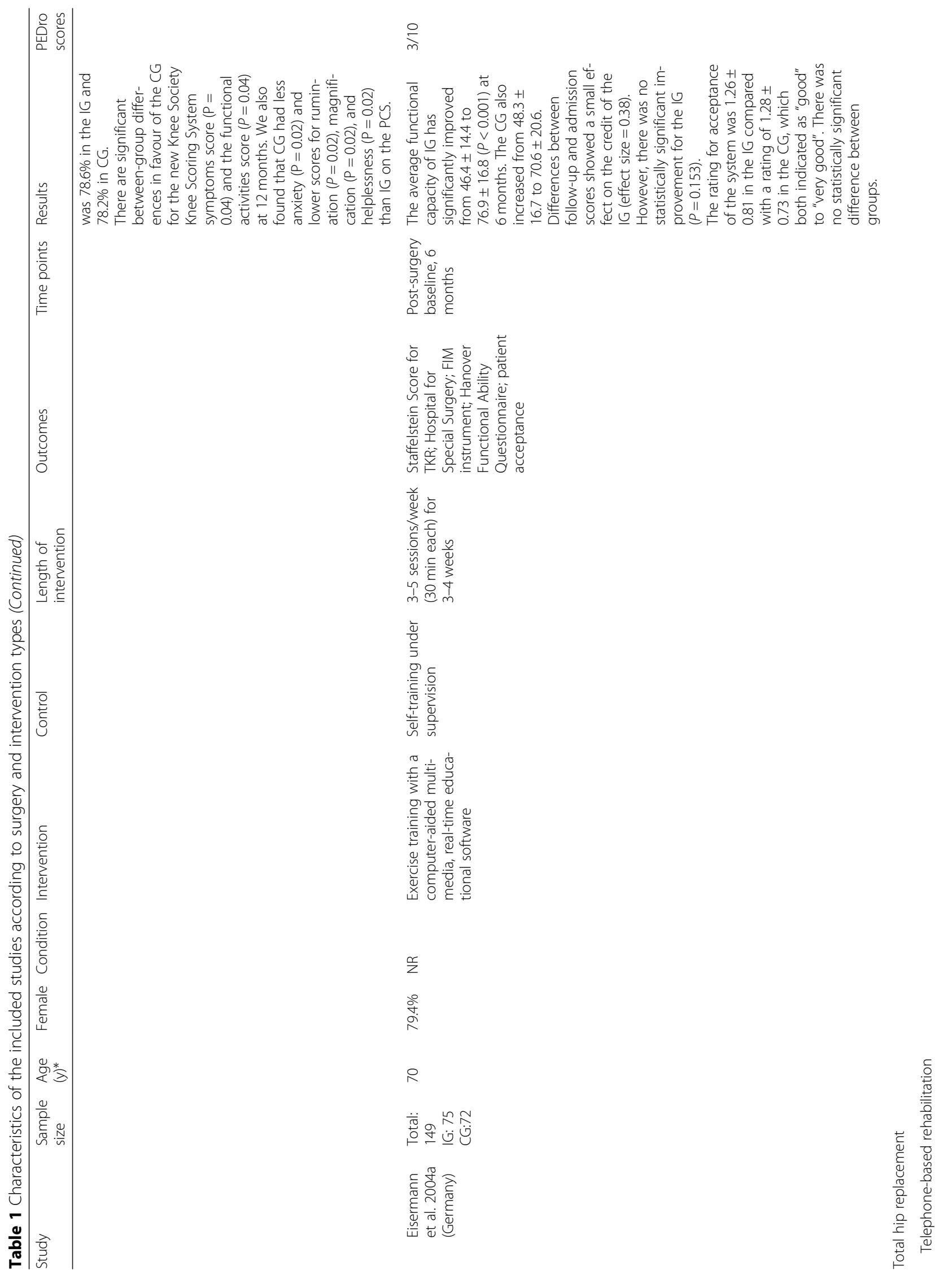




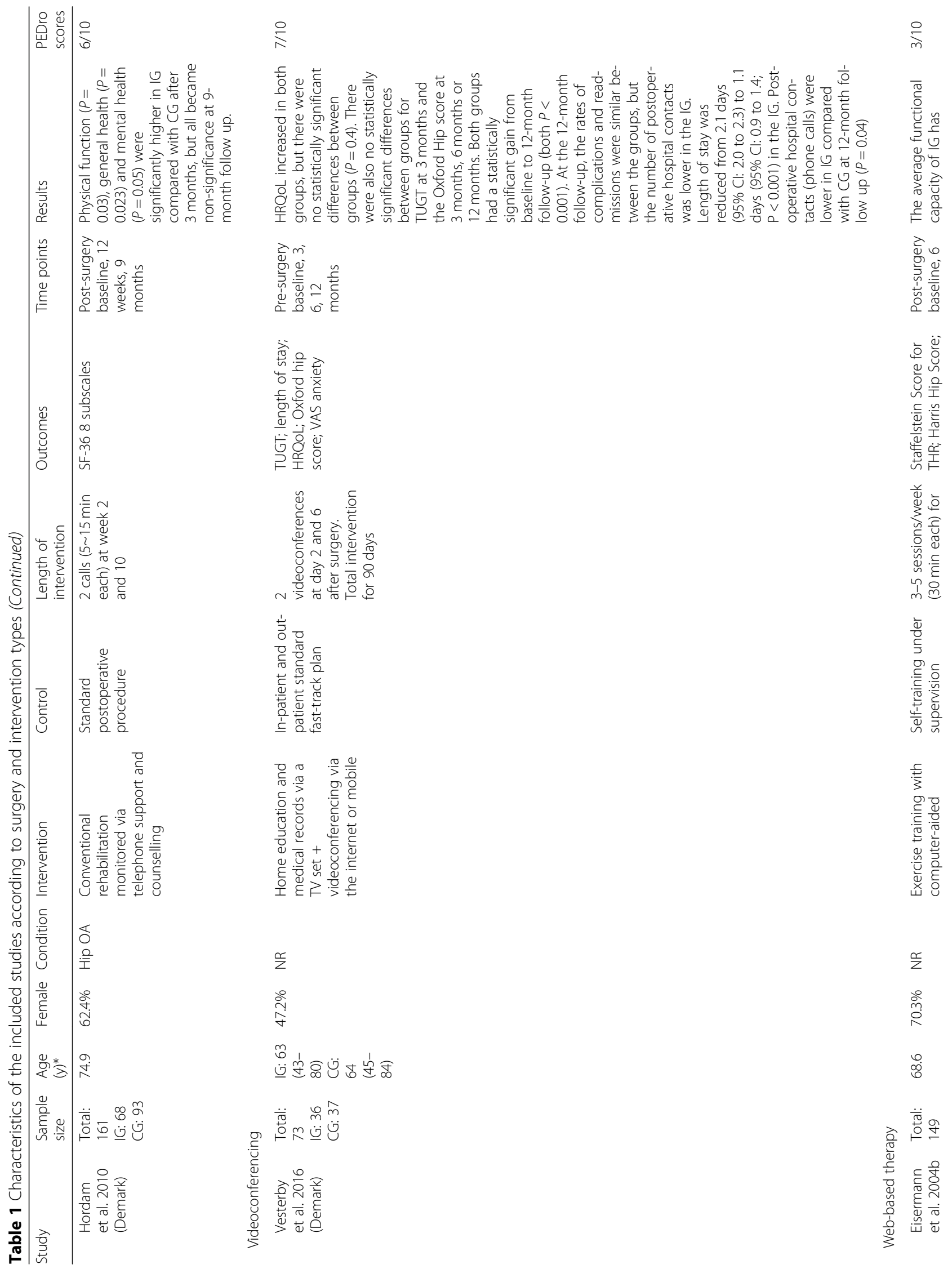




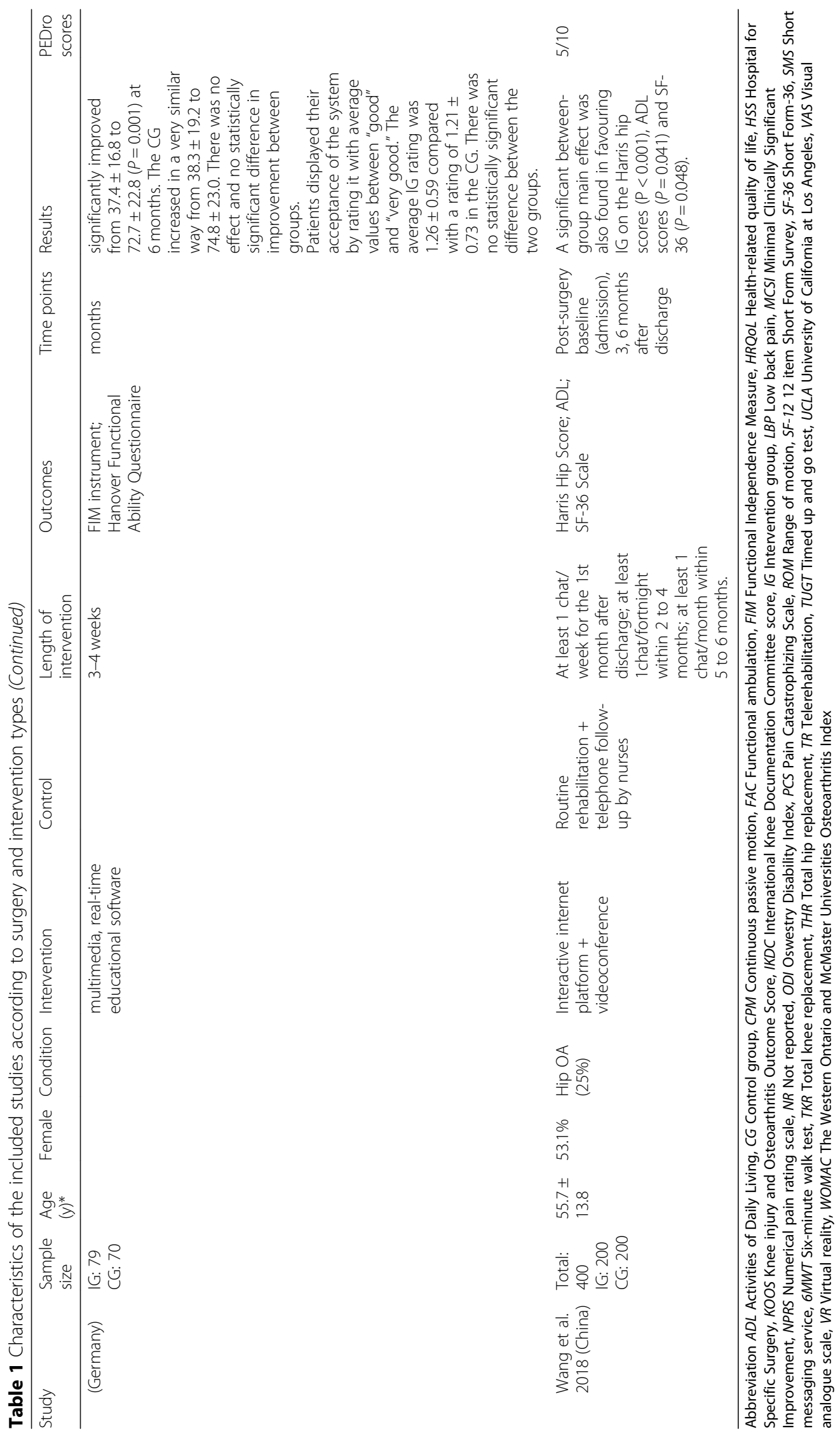




\begin{tabular}{|c|c|c|c|c|c|c|c|c|c|c|}
\hline \multirow[b]{2}{*}{ Study or Subgroup } & \multicolumn{3}{|c|}{ Intervention } & \multicolumn{3}{|c|}{ Control } & \multirow[b]{2}{*}{ Weight } & \multirow{2}{*}{$\begin{array}{l}\text { Mean Difference } \\
\text { IV, Random, } 95 \% \mathrm{CI}\end{array}$} & \multirow{2}{*}{\multicolumn{2}{|c|}{$\begin{array}{l}\text { Mean Difference } \\
\text { IV, Random, } 95 \% \mathrm{CI}\end{array}$}} \\
\hline & Mean & SD & Total & Mean & SD & Total & & & & \\
\hline \multicolumn{11}{|c|}{ 1.1.1 TKR - Telerehabilitation } \\
\hline Chen 2016 & 1.61 & 0.62 & 101 & 1.84 & 0.67 & 101 & $47.1 \%$ & $-0.23[-0.41,-0.05]$ & - & \\
\hline Piqueras 2013 & -0.69 & 1.44 & 72 & -0.61 & 1.87 & 70 & $14.0 \%$ & $-0.08[-0.63,0.47]$ & & \\
\hline $\begin{array}{l}\text { Russell } 2011 \\
\text { Subtotal }(95 \% \mathrm{Cl})\end{array}$ & -3.07 & 1.55 & $\begin{array}{r}31 \\
204\end{array}$ & -3.29 & 1.31 & $\begin{array}{r}34 \\
205\end{array}$ & $\begin{array}{r}9.4 \% \\
70.5 \%\end{array}$ & $\begin{array}{r}0.22[-0.48,0.92] \\
-0.19[-0.36,-0.03]\end{array}$ & & \\
\hline \multicolumn{11}{|c|}{$\begin{array}{l}\text { Heterogeneity: } \text { Tau }^{2}=0.00 ; \mathrm{Chi}^{2}=1.66, \mathrm{df}=2(P=0.44) ; I^{2}=0 \% \\
\text { Test for overall effect: } Z=2.28(P=0.02)\end{array}$} \\
\hline \multicolumn{11}{|c|}{ 1.1.2 TKR - Web-based therapy } \\
\hline Bini 2016 & -3.43 & 2.68 & 14 & -4 & 3.23 & 15 & $1.1 \%$ & $0.57[-1.58,2.72]$ & & \\
\hline \multicolumn{11}{|c|}{ 1.1.3 TKR - Game-based therapy } \\
\hline Jin 2018 & 3.87 & 0.55 & 33 & 4.42 & 0.79 & 33 & $28.3 \%$ & $-0.55[-0.88,-0.22]$ & $\longrightarrow$ & \\
\hline \multirow{2}{*}{\multicolumn{9}{|c|}{$\begin{array}{l}\text { Total }(95 \% \mathrm{Cl}) \quad 251 \quad 253 \quad 100.0 \%-0.25[-0.48,-0.02] \\
\text { Heterogeneity: } \text { Tau }^{2}=0.02 ; \mathrm{Chi}^{2}=5.89, \mathrm{df}=4(\mathrm{P}=0.21) ; \mathrm{I}^{2}=32 \% \\
\text { Test for overall effect: } \mathrm{Z}=2.09(\mathrm{P}=0.04) \\
\text { Test for subgroup differences: } \mathrm{Chi}^{2}=4.23, \mathrm{df}=2(\mathrm{P}=0.12), \mathrm{I}^{2}=52.7 \%\end{array}$}} & & \\
\hline & & & & & & & & & $\begin{array}{ccc}1 & 1 \\
-2 & -1 & 0 \\
\text { Favours [Intervention] }\end{array}$ & $\begin{array}{cc}1 & 1 \\
\text { Favours [Control] } & 2\end{array}$ \\
\hline \multicolumn{11}{|c|}{$\begin{array}{l}\text { Fig. } 2 \text { Pooled effect of trials that investigated the effects of digital rehabilitation versus usual care on the visual analogue scale for pain: scale from } 0 \text { to } \\
\text { 10, with higher scores indicating higher pain severity. Squares represent each individual study. Diamonds represent the pooled effect. Weight (\%) } \\
\text { represents the influence of each study on the overall meta-analysis. Cl, confidence interval; TKR, total knee replacement; } I^{2} \text {, heterogeneity of studies }\end{array}$} \\
\hline
\end{tabular}

\section{Secondary outcomes}

Quality of life Six trials (TKR: $N=520$; THR: $N=161$ ) investigated the effect of telerehabilitation on quality of life (Table 1) [27, 33, 34, 36, 38, 44]. Meta-analysis was not feasible due to differences in completeness of reported data and inconsistent measurements. Two trials in people who underwent rehabilitation after TKR reported that telerehabilitation showed significant improvements on short form (SF)-36 mental component score $(P<0.01)[27]$ and physical function subscale $(P=$ 0.031) [33], respectively. One study of THR showed physical function $(\mathrm{P}=0.03)$, general health $(P=0.023)$ and mental health $(P=0.05)$ subscales of SF-36 were all significantly higher in the telerehabilitation group compared with the control group after 3 months, but all became non-significance at 9-month follow-up [38].

Adherence and user experience Three RCTs of 472 people undergoing TKR investigated their compliance through an exercise diary [27, 31, 32]. One study showed the average time of daily home exercise in the telerehabilitation group (54.12 \pm 5.71 mins) was significantly higher than the control group (48.95 \pm 7.21 mins) [27]. Two studies showed no between-group differences in the number of exercise sessions finished daily [31, 32].

Four trials $(N=757)$ reported user experience and showed similar levels of satisfaction with both the intervention and the control $[40,43,44,48]$. One trial of an educational software demonstrated positive user experiences, such as good clarity of instruction, ease of taking or sharing a video and ease of seeing their progress [44]. Another study of training software also received positive feedback from participants and therapists [43]. When participants were asked what they liked most about the application, no travelling to the hospital was cited by $57 \%$ and ease of access by $21 \%$ [44].

Safety Moderate quality evidence from 3 RCTs $(N=667)$ showed the total number of serious adverse events (SAEs) were higher in the intervention group comparing to usual care (38 vs. 27) [29-31] (Table 2). However, there were no SAEs related to the intervention, while 2 events in the usual care group: one fell and one had wound bleeding during the first knee flexion exercise [31]. Of all the patients who had hospital admissions related knee issues, one in the usual care group had a leg blister below the TKR site, 3 in the usual care and 4 in the telerehabilitation group received manipulation under anaesthesia [30, 31]; one participant in the telerehabilitation group had thrombophlebitis [31]. One THR patient in the intervention group had a fever [29].

\section{Discussion}

Our review found that moderate-quality of evidence showed technology-assisted rehabilitation, in particular, telerehabilitation, had a statistically significant improvement in pain; and low-quality of evidence for the improvement in functional mobility in people undergoing TKR. The effects were however small and of arguable clinical significance. For THR, there is very limited lowquality evidence shows no significant effects. Preplanned sub-group meta-analyses on study design (i.e. technology-based rehabilitation alone or in addition to usual care) were not performed due to insufficient studies. Most of the trials only had short-term follow-ups, therefore, the long-term effectiveness of technologyassisted rehabilitation was not ascertained.

Compared to previous studies in the field, our review has identified more than twice the number of the trials and most of the new studies added in our meta-analyses 
Table 2 Summary of the quality of evidence and strength of recommendation according to Grading of Recommendations Assessment, Development and Evaluation (GRADE) criteria

\begin{tabular}{|c|c|c|c|c|c|c|c|c|c|}
\hline \multicolumn{6}{|c|}{ Certainty assessment } & \multicolumn{2}{|c|}{$\begin{array}{l}\text { № of (events/) } \\
\text { participants }\end{array}$} & \multirow{2}{*}{$\begin{array}{l}\text { Quality } \\
\text { Overall certainty of } \\
\text { evidence }\end{array}$} & \multirow{2}{*}{$\begin{array}{l}\text { Importance } \\
\text { Importance of } \text { outcomes }^{\mathrm{a}}\end{array}$} \\
\hline № of studies & Risk of bias & Inconsistency & Indirectness & Imprecision & Publication bias & Intervention & Control & & \\
\hline \multicolumn{10}{|c|}{ Pain (follow up: from 2 weeks to 3 months; assessed with: Visual Analogue Scale) } \\
\hline $\begin{array}{l}3 \text { RCTs } \\
{[27,32,37]}\end{array}$ & Serious ${ }^{\mathrm{f}}$ & Not serious & Not serious & Not serious & None ${ }^{m}$ & 204 & 205 & $\oplus \oplus \circ \circ$ Moderate & Critical \\
\hline \multicolumn{10}{|c|}{ Function (follow up: range from 2 weeks to 3 months; assessed with: Timed Up and Go test) } \\
\hline $\begin{array}{l}2 \mathrm{RCTS} \\
{[32,37]}\end{array}$ & Serious ${ }^{\mathrm{f}}$ & Serious $^{\mathrm{h}}$ & Not serious & Serious ${ }^{i}$ & None ${ }^{m}$ & 103 & 104 & $\oplus \circ 00$ Very low & Critical \\
\hline \multicolumn{10}{|c|}{ Mobility (follow up: range from 2 months to 3 months; assessed with: Six-Minute Walk Test) } \\
\hline $\begin{array}{l}2 \mathrm{RCTS} \\
{[31,41]}\end{array}$ & Serious ${ }^{f}$ & Serious ${ }^{\mathrm{h}}$ & Serious ${ }^{g}$ & Very seriousi, 1 & None $^{m}$ & 128 & 130 & $\oplus \oplus \circ \circ$ Very low & Critical \\
\hline \multicolumn{10}{|c|}{ Serious adverse events ${ }^{\mathrm{b}}$ (follow up: range 6 weeks to 4 months) } \\
\hline $\begin{array}{l}3 \text { RCTs } \\
\text { [29-31] }\end{array}$ & Not serious & Not serious & Serious ${ }^{j}$ & Not serious & None ${ }^{m}$ & $\begin{array}{l}38 / 334 \\
(11.4 \%)\end{array}$ & $\begin{array}{l}27 / 333 \\
(8.1 \%)^{d}\end{array}$ & $\oplus \oplus \oplus \circ$ Moderate & Critical \\
\hline \multicolumn{10}{|c|}{ Treatment-related adverse events ${ }^{c}$ (follow up: range 6 weeks to 4 months) } \\
\hline $\begin{array}{l}2 \text { RCTs } \\
{[29,31]}\end{array}$ & Not serious & Not assessed ${ }^{k}$ & Not serious & Not assessed ${ }^{k}$ & None $^{\mathrm{m}}$ & $\begin{array}{l}9 / 251 \\
(3.1 \%)\end{array}$ & $\begin{array}{l}8 / 256 \\
(3.6 \%)^{\mathrm{e}}\end{array}$ & $\oplus \oplus \oplus \circ$ Moderate & Critical \\
\hline
\end{tabular}

Abbreviations: GRADE Grading of recommendations assessment, development and evaluation, RCT Randomised controlled trial GRADE Working Group grades of evidence

High certainty: We are very confident that the true effect lies close to that of the estimate of the effect

Moderate certainty: We are moderately confident in the effect estimate: The true effect is likely to be close to the estimate of the effect, but there is a possibility that it is substantially different

Low certainty: Our confidence in the effect estimate is limited: The true effect may be substantially different from the estimate of the effectVery low certainty: We have very little confidence in the effect estimate: The true effect is likely to be substantially different from the estimate of effect Explanation

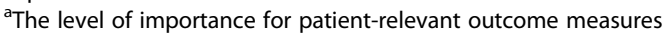

${ }^{b}$ Serious adverse events include: hospital readmission for leg blister, manipulation under aesthesia for poor knee range of motion, prostate check and cataract surgery (Han 2015); death, hospitalization, manipulation under aesthesia, degradation of the general condition, hip fracture due to fall, gastrointestinal disorder, rheumatologic disorder, cardiac arrhythmia, thrombophlebitis, spinal surgery, inguinal hernia surgery, cystocele surgery, retinal detachment surgery, total knee arthroplasty on contralateral side (Moffet 2016)

'Treatment-related adverse events include: operated knee swelling and/or extreme knee pain; excess wound leakage or bleeding (Han et al., 2015)

${ }^{\mathrm{d}}$ Risk difference with intervention: 33 more per 1000 (from 9 fewer to 100 more)

e Risk difference with intervention: 6 more per 1000 (from 17 fewer to 67 more)

${ }^{\mathrm{f}}$ More than $25 \%$ of participants from studies with low methodological quality (Physiotherapy Evidence Database score $<7$ points)

${ }^{9}$ Different technologies were analysed together (Moffet 2016 - telerehabilitation; Li 2014 - game-based therapy)

$\mathrm{h}^{2}>50 \%$; substantial heterogeneity

'Small sample size: $<400$ participants in the pooling.

${ }^{\mathrm{j} A}$ mixed population of hip and knee replacement: $10 \%$ of patients have total hip replacement (Vesterby 2016 - hip replacement-only study)

kZero events were reported in one of the trials.

'95\% Cl overlaps no effects (i.e. fails to exclude important benefit or important harm)

${ }^{m}$ The possibility of publication bias is not excluded but it was not considered as sufficient to downgrade the quality of evidence

had higher methodological quality. For instance, the most recent systematic review only included 8 RCTs of post-TKR rehabilitation and 3 RCTs of post-THR rehabilitation and only provided a qualitative evaluation of those studies [15]. It concluded that the evidence was strong based on a PEDro score $\geq 5$, which seems to be overestimated [49].

From the few studies that investigated user experience, there is a trend towards a positive impact of telerehabilitation, particularly, adherence to physical activities and compliance to rehabilitation programs [27, 31, 32]. Although the majority of the study population were older adults, their use of technologies, such as smartphone was quite high (59-49\%) [50]. Similarly, in older adults with no prior experience with game consoles, most of them were highly motivated and expressed enjoyment in using the Wii Fit [39] and 86\% of them were willing to continue the game therapy at home [40]. Some barriers were also demonstrated, such as poor internet connection at the participant's home, delayed technology installation [32] and poor visual quality of the videoconference [32]. Additionally, older people may experience technological adoption barriers, such as concerns about the cost and battery life of the devices, as well as lack of familiarity with the technology [51]. These highlighted the need for cost-effective and powerefficient devices, elderly user-friendly design, sufficient training and ongoing customer support.

Importantly, the innovative devices or digital technologies should not be viewed as a distinct modality of care, 


\begin{tabular}{|c|c|c|c|c|c|c|c|c|c|}
\hline \multirow[b]{2}{*}{ Study or Subgroup } & \multicolumn{3}{|c|}{ Intervention } & \multicolumn{3}{|c|}{ Control } & \multirow[b]{2}{*}{ Weight } & \multirow{2}{*}{$\begin{array}{l}\text { Mean Difference } \\
\text { IV, Random, } 95 \% \mathrm{CI}\end{array}$} & \multirow{2}{*}{$\begin{array}{c}\text { Mean Difference } \\
\text { IV, Random, } 95 \% \mathrm{CI}\end{array}$} \\
\hline & Mean & SD & Total & Mean & SD & Total & & & \\
\hline \multicolumn{10}{|c|}{ 1.2.1 TKR - Telerehabilitation } \\
\hline Piqueras 2013 & -3.36 & 5.38 & 72 & 5.22 & 6.25 & 70 & $35.0 \%$ & $-8.58[-10.50,-6.66]$ & \multirow[t]{2}{*}{ - - } \\
\hline $\begin{array}{l}\text { Russell } 2011 \\
\text { Subtotal }(95 \% \mathrm{Cl})\end{array}$ & -16.33 & 10.94 & $\begin{array}{r}31 \\
103\end{array}$ & -12.19 & 10.12 & $\begin{array}{r}34 \\
104\end{array}$ & $\begin{array}{l}28.9 \% \\
63.9 \%\end{array}$ & $\begin{array}{r}-4.14[-9.28,1.00] \\
-7.03[-11.18,-2.88]\end{array}$ & \\
\hline \multicolumn{10}{|c|}{$\begin{array}{l}\text { Heterogeneity: } \mathrm{Tau}^{2}=5.94 ; \mathrm{Chi}^{2}=2.52, \mathrm{df}=1(\mathrm{P}=0.11) ; \mathrm{I}^{2}=60 \% \\
\text { Test for overall effect: } Z=3.32(P=0.0009)\end{array}$} \\
\hline \multicolumn{10}{|c|}{ 1.2.3 THR - Telerehabilitation } \\
\hline Vesterby 2017 & -2.1 & 1.7733 & 36 & -1.4 & 1.5664 & 36 & $36.1 \%$ & $-0.70[-1.47,0.07]$ & - \\
\hline \multirow{2}{*}{\multicolumn{9}{|c|}{ 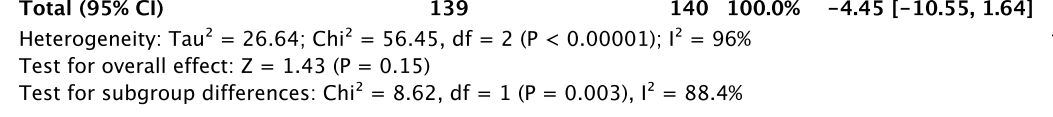 }} & \\
\hline & & & & & & & & & $\begin{array}{ccccc}-10 & -5 & 0 & 5 & 10 \\
\text { Favours [Intervention] } & \text { Favours [Control] }\end{array}$ \\
\hline \multicolumn{10}{|c|}{$\begin{array}{l}\text { Fig. } 3 \text { Pooled effect of trials that investigated the effects of digital rehabilitation versus usual care on timed up and go test: assessed in second, } \\
\text { with a higher number indicating worse functional ability. Squares represent each individual study. Diamonds represent the pooled effect. Weight } \\
\text { (\%) represents the influence of each study on the overall meta-analysis. Cl, confidence interval; TKR, total knee replacement; THR, total hip replacement; } \\
I^{2} \text {, heterogeneity of studies }\end{array}$} \\
\hline
\end{tabular}

but rather used as an aid/adjunct to bridge gaps or accelerate efficiency in existing healthcare delivery systems [52]. A study showed that telerehabilitation in addition to usual care was more favourable than usual care alone, whilst treatment delivered solely via telerehabilitation was equivalent to face-to-face intervention for functional improvement in people with MSK conditions [16]. In addition, validity studies reported a good agreement between face-to-face and telehealth assessment of MSK disorders of the knee (exact agreement of primary pathoanatomical diagnoses was 67\%) [53]. Given the fact that technology could improve the healthcare accessibility and treatment adherence, despite its clinical effectiveness was similar comparing to conventional intervention, it still has a very promising role in circumstances when access and adherence are challenging.

Apart from some practical issues of licensure, there are potential challenges when implementing digital technologies in clinical practice. Firstly, the safety of the technology-assisted rehabilitation needs to be better understood. In our review, only a handful of studies reported AEs, although they all showed no increased harm. For game-based therapy, trials in the current review did not report any AEs, but it is reported that dynamic movements followed by different games can increase falls risks or other MSK injuries [54]. Safeguards should be taken pre-emptively when emergencies need to be solved virtually [55]. Healthcare providers embarking on careers in innovative technologies should be aware of current legal regulations to minimise risk [55]. Cost can also be a barrier when certain technology was first developed, thus, high-quality cost-effectiveness analyses are needed to demonstrate the long-term economic benefits.

There are several limitations to our review. Many studies did not perform a priori sample size calculations, which can increase the risk of underpowered (false-negative) results. Secondly, the trials used varied outcome measures which limited the pooling of results. Consensus on a set of suitable outcome measures needs to be reached for future trials. Furthermore, there is insufficient long-term follow up for ensuring the prolonged effects or safety. Lastly, a common risk of bias of the studies is a lack of blinding. As blinding of participants and therapists is not possible for most pragmatic trials, including those of technology-based rehabilitation interventions, future research should pay attention to the methodological aspects to minimise the biases.

\section{Conclusion}

There is moderate- to low-quality of evidence that current technology-enabled rehabilitation, in particular, telerehabilitation, showed most improvements in pain and function for people following TKR, comparing to usual rehabilitation. However, the effect size was too

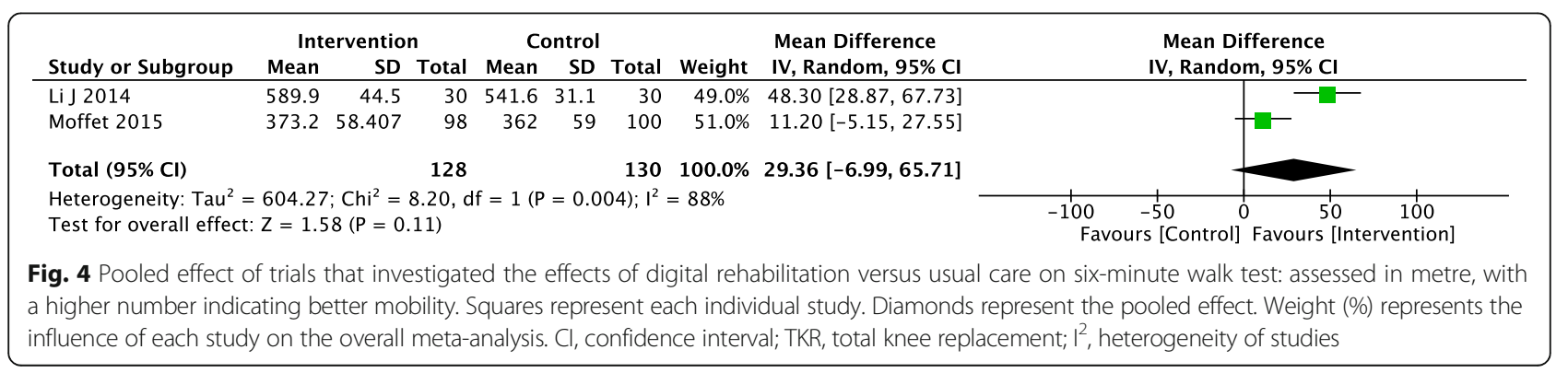


small to be clinically significant. Further high-quality studies are needed to demonstrate the long-term efficacy and safety of innovative health technologies, especially for post-THR rehabilitation.

\section{Supplementary information}

Supplementary information accompanies this paper at https://doi.org/10. 1186/s12891-019-2900-x.

\section{Additional file 1: Appendix 1. Search strategies}

Additional file 2: Figure S1. Pooled effect of trials that investigated the effects of digital rehabilitation versus usual care on the Western Ontario and McMaster Universities Osteoarthritis Index function scores (5-point Likert scale). Squares represent each individual study. Diamonds represent the pooled effect. Weight (\%) represents the influence of each study on the overall meta-analysis. $\mathrm{Cl}$, confidence interval; $\mathrm{I}^{2}$, heterogeneity of studies. Figure S2. Pooled effect of trials that investigated the effects of digital rehabilitation versus usual care on the Western Ontario and McMaster Universities Osteoarthritis Index pain scores (5-point Likert scale). Squares represent each individual study. Diamonds represent the pooled effect. Weight (\%) represents the influence of each study on the overall meta-analysis. Cl, confidence interval; $\mathrm{I}^{2}$, heterogeneity of studies. Figure S3. Pooled effect of trials that investigated the effects of digital rehabilitation versus usual care on the Western Ontario and McMaster Universities Osteoarthritis Index stiffness scores (5-point Likert scale). Squares represent each individual study. Diamonds represent the pooled effect. Weight (\%) represents the influence of each study on the overall meta-analysis. $\mathrm{Cl}$, confidence interval; $\mathrm{I}^{2}$, heterogeneity of studies.

\section{Abbreviations}

6MWT: 6 Minute Walking Test; GRADE: Grading of Recommendations, Assessment, Development and Evaluation; ICCs: Intraclass correlation coefficient; MD: Mean difference; MSK: Musculoskeletal; NHMRC: National Health and Medical Research Council; ORs: Odds ratios; PEDro: Physiotherapy Evidence Database; PRISMA: Preferred Reporting Items for Systematic Reviews and Meta-Analysis; RCTs: Randomised controlled trials; RRs: Risk ratios; SAEs: Serious adverse events; SDs: Standard deviations; SEs: Standard errors; SF: Short form; SMD: Standardised MDs; THR: Total hip replacement; TKR: Total knee replacement; TUGT: Time up and Go Test; VR: Virtual reality; WOMAC: Western Ontario and McMaster Universities Osteoarthritis Index

\section{Acknowledgements}

We want to thank the librarian, Yulia Ulyannikova from the University of Sydney in assisting the development of the search strategies.

\section{Authors' contributions}

XW, DJH, GV, DP, MLF contributed to conceptualization, data curation, formal analysis, investigation, methodology, project administration, writing, reviewing and editing the final manuscript. DJH and MLF are responsible for funding acquisition, project supervision and data validation. All authors have read and approved the final manuscript.

\section{Funding}

This work has been supported by the Ramsay Research Foundation. DJH is supported by a National Health and Medical Research Council (NHMRC) Practitioner Fellowship. MLF is funded by a NHMRC Career Development Fellowship and a Sydney Medical Foundation Fellowship. The funding sources did not play a role in the design or conduct of the study.

\section{Availability of data and materials}

All data generated or analysed during this study are included in this published article [and its supplementary information files].

\section{Ethics approval and consent to participate}

Not applicable.

\section{Consent for publication}

Not applicable.

\section{Competing interests}

Professor Hunter provides consulting advice for Pfizer, Lilly, TLC bio and Merck Serono. Associate Professor Manuela L. Ferreira is a member of the editorial board of this journal. All other authors have no competing interests.

\section{Author details}

'Level 10 Kolling Institute, Institute of Bone and Joint Research, Royal North Shore Hospital, University of Sydney, Reserve Road, St. Leonards, Sydney, NSW 2065, Australia. ${ }^{2}$ Department of Gynaecology and Obstetrics, Botucatu Medical School, San Paulo State University, São Paulo, Brazil.

\section{Received: 20 May 2019 Accepted: 16 October 2019}

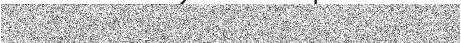

\section{References}

1. Disease GBD, Injury I, Prevalence C. Global, regional, and national incidence, prevalence, and years lived with disability for 310 diseases and injuries, 1990-2015: a systematic analysis for the global burden of disease study 2015. Lancet. 2016;388(10053):1545-602.

2. Australian Orthopaedic Association National Joint Replacement Registry Analysis of state and territory health data all arthroplasty, annual report. Adelaide: AOA; 2017.

3. Royal Australasian College of Surgeons 2018. Rehabilitation pathways following hip and knee arthroplasty. North Adelaide: Royal Australasian College of Surgeons; 2018.

4. Peretti A, Amenta F, Tayebati SK, Nittari G, Mahdi SS. Telerehabilitation: review of the state-of-the-art and areas of application. JMIR Rehabil Assist Technol. 2017:4(2):e7.

5. Christensen $\mathrm{C}$. The innovator's dilemma: when new technologies cause great firms to fail. Boston: Harvard Business Review Press; 2013.

6. Amatya B, Galea MP, Kesselring J, Khan F. "Effectiveness of telerehabilitation interventions in persons with multiple sclerosis: A systematic review." Multiple sclerosis and related disorders 4.4. 2015:358-369.

7. Cotelli M, Manenti R, Brambilla M, Gobbi E, Ferrari C, Binetti G, et al. Cognitive telerehabilitation in mild cognitive impairment, Alzheimer's disease and frontotemporal dementia: a systematic review. J Telemed Telecare. 2017. https://doi.org/10.1177/1357633×17740390.

8. Cramer SC, Dodakian L, Le V, See J, Augsburger R, McKenzie A, Zhou RJ, Chiu NL, Heckhausen J, Cassidy JM, Scacchi W. Efficacy of Home-Based Telerehabilitation vs In-Clinic Therapy for Adults After Stroke: A Randomized Clinical Trial. JAMA neurology. 2019;76(9):1079-1087.

9. Cheville AL, Moynihan T, Herrin J, Loprinzi C, Kroenke K. Effect of collaborative telerehabilitation on functional impairment and pain among patients with advanced-stage cancer: a randomized clinical trial. JAMA Oncol. 2019;5(5):644-652.

10. Chan C, Yamabayashi C, Syed N, Kirkham A, Camp PG. Exercise Telemonitoring and Telerehabilitation compared with traditional cardiac and pulmonary rehabilitation: a systematic review and meta-analysis. Physiother Can. 2016;68(3):242-51.

11. Reeder B, Chung J, Stevens-Lapsley J. Current telerehabilitation research with older adults at home: an integrative review. J Gerontol Nurs. 2016; 42(10):15-20.

12. Patel $S$, Park $H$, Bonato $P$, Chan $L$, Rodgers $M$. A review of wearable sensors and systems with application in rehabilitation. J Neuroeng Rehabil. 2012; $9(1): 21$.

13. Weiss PL, Sveistrup H, Rand D, Kizony R. Video capture virtual reality: a decade of rehabilitation assessment and intervention. Phys Ther Rev. 2009; 14(5):307-21.

14. Mair F, Whitten P. Systematic review of studies of patient satisfaction with telemedicine. BMJ. 2000;320(7248):1517-20.

15. Pastora-Bernal JM, Martin-Valero R, Baron-Lopez FJ, Estebanez-Perez MJ. Evidence of benefit of Telerehabitation after orthopedic surgery: a systematic review. J Med Internet Res. 2017;19(4):e142.

16. Cottrell MA, Galea OA, O'Leary SP, Hill AJ, Russell TG. Real-time telerehabilitation for the treatment of musculoskeletal conditions is effective and comparable to standard practice: a systematic review and metaanalysis. Clin Rehabil. 2017:31(5):625-38.

17. Shukla H, Nair SR, Thakker D. Role of telerehabilitation in patients following total knee arthroplasty: evidence from a systematic literature review and meta-analysis. J Telemed Telecare. 2017;23(2):339-46. 
18. Wang X, Hunter DJ, Vesentini G, Pozzobon D, Ferreira ML. Technologyassisted rehabilitation following total knee or hip replacement for people with osteoarthritis: a systematic review and meta analysis. Osteoarthr Cartil. 2019;27:S443.

19. Moher D, Liberati A, Tetzlaff J, Altman DG. Preferred reporting items for systematic reviews and meta-analyses: the PRISMA statement. Annals of internal medicine. 2009;151(4):264-9.

20. Maher CG, Sherrington C, Herbert RD, Moseley AM, Elkins M. Reliability of the PEDro scale for rating quality of randomized controlled trials. Phys Ther. 2003:83(8):713-21.

21. de Morton NA. The PEDro scale is a valid measure of the methodological quality of clinical trials: a demographic study. Aust J Physiother. 2009;55(2): 129-33.

22. Macedo LG, Elkins MR, Maher CG, Moseley AM, Herbert RD, Sherrington C. There was evidence of convergent and construct validity of physiotherapy evidence database quality scale for physiotherapy trials. J Clin Epidemiol. 2010;63(8):920-5.

23. Gill SD, McBurney $H$. Does exercise reduce pain and improve physical function before hip or knee replacement surgery? A systematic review and meta-analysis of randomized controlled trials. Arch Phys Med Rehabil. 2013; 94(1):164-76.

24. Guyatt GH, Oxman AD, Schunemann HJ, Tugwell P, Knottnerus A. GRADE guidelines: a new series of articles in the journal of clinical epidemiology. J Clin Epidemiol. 2011;64(4):380-2.

25. Lewis S, Clarke M. Forest plots: trying to see the wood and the trees. BMJ. 2001;322(7300):1479-80.

26. Higgins JP, Green S. Cochrane handbook for systematic reviews of interventions. Chichester, West Sussex: Wiley; 2011.

27. Chen M, Li P, Lin F. Influence of structured telephone follow-up on patient compliance with rehabilitation after total knee arthroplasty. Patient Prefer Adherence. 2016;10:257-64.

28. Christiansen CL, Bade MJ, Davidson BS, Dayton MR, Stevens-Lapsley JE. Effects of weight-bearing biofeedback training on functional movement patterns following Total knee arthroplasty: a randomized controlled trial. J Orthop Sports Phys Ther. 2015;45(9):647-55.

29. Vesterby MS, Pedersen PU, Laursen M, Mikkelsen S, Larsen J, Soballe $K$, et al. Telemedicine support shortens length of stay after fast-track hip replacement a randomized controlled trial. Acta Orthop. 2017; 88(1):41-7.

30. Han ASY, Nairn L, Harmer AR, Crosbie J, March L, Parker D, et al. Early rehabilitation after Total knee replacement surgery: a multicenter, noninferiority, randomized clinical trial comparing a home exercise program with usual outpatient care. Arthritis Care Res. 2015;67(2):196-202.

31. Moffet $H$, Tousignant M, Nadeau S, Merette C, Boissy P, Corriveau H, et al. In-home Telerehabilitation compared with face-to-face rehabilitation after Total knee arthroplasty a noninferiority randomized controlled trial. J Bone Joint Surg Am. 2015;97a(14):1129-41.

32. Russell TG, Buttrum P, Wootton R, Jull GA. Internet-based outpatient telerehabilitation for patients following total knee arthroplasty: a randomized controlled trial. J Bone Joint Surg Am. 2011;93(2):113-20.

33. Szots K, Konradsen H, Solgaard S, Ostergaard B. Telephone follow-up by nurse after Total knee arthroplasty: results of a randomized clinical trial. Orthop Nurs. 2016;35(6):411-20.

34. Kramer JF, Speechley M, Bourne R, Rorabeck C, Vaz M. Comparison of clinicand home-based rehabilitation programs after total knee arthroplasty. Clin Orthop Relat Res. 2003;410(410):225-34.

35. Park KH, Song MR. The effects of Postdischarge telephone counseling and short message service on the knee function, activities of daily living, and life satisfaction of patients undergoing Total knee replacement. Orthop Nurs. 2017;36(3):229-36.

36. Tousignant M, Moffet $H$, Boissy P, Corriveau H, Cabana F, Marquis F. A randomized controlled trial of home telerehabilitation for post-knee arthroplasty. J Telemed Telecare. 2011;17(4):195-8.

37. Piqueras M, Marco E, Coll M, Escalada F, Ballester A, Cinca C, et al. Effectiveness of an interactive virtual telerehabilitation system in patients after total knee arthoplasty: a randomized controlled trial. J Rehabil Med. 2013;45(4):392-6.

38. Hordam B, Sabroe S, Pedersen PU, Mejdahl S, Soballe K. Nursing intervention by telephone interviews of patients aged over 65 years after total hip replacement improves health status: a randomised clinical trial. Scand J Caring Sci. 2010;24(1):94-100.
39. Ficklscherer A, Stapf J, Meissner KM, Niethammer T, Lahner M, Wagenhauser $\mathrm{M}$, et al. Testing the feasibility and safety of the Nintendo Wii gaming console in orthopedic rehabilitation: a pilot randomized controlled study. Arch Med Sci. 2016;12(6):1273-8.

40. Fung V, Ho A, Shaffer J, Chung E, Gomez M. Use of Nintendo Wii fit in the rehabilitation of outpatients following total knee replacement: a preliminary randomised controlled trial. Physiotherapy. 2012;98(3):183-8.

41. Li J, Wu T, Xu Z, Gu X. A pilot study of post-total knee replacement gait rehabilitation using lower limbs robot-assisted training system. Eur J Orthop Surg Traumatol. 2014;24(2):203-8.

42. Jin C, Feng YJ, Ni YJ, Shan ZL. Virtual reality intervention in postoperative rehabilitation after total knee arthroplasty: a prospective and randomized controlled clinical trial. Int J Clin Exp Med. 2018;11(6):6119-24.

43. Eisermann U, Haase I, Kladny B. Computer-aided multimedia training in orthopedic rehabilitation. Am J Phys Med Rehabil. 2004;83(9):670-80.

44. Bini SA, Mahajan J. Clinical outcomes of remote asynchronous telerehabilitation are equivalent to traditional therapy following total knee arthroplasty: a randomized control study. J Telemed Telecare. 2017;23(2): 239-47.

45. Mathias S, Nayak USL, Isaacs B. Balance in elderly patients - the get-up and go test. Arch Phys Med Rehabil. 1986;67(6):387-9.

46. Hamilton DM, Haennel R. Validity and reliability of the 6-minute walk test in a cardiac rehabilitation population. J Cardiopulm Rehabil Prev. 2000;20(3): 156-64.

47. Bellamy N, Buchanan WW, Goldsmith CH, Campbell J, Stitt LW. Validation study of WOMAC: a health status instrument for measuring clinically important patient relevant outcomes to antirheumatic drug therapy in patients with osteoarthritis of the hip or knee. J Rheumatol. 1988;15(12): 1833-40.

48. Culliton SE, Bryant DM, MacDonald SJ, Hibbert KM, Chesworth BM. Effect of an e-learning tool on expectations and satisfaction following Total knee arthroplasty: a randomized controlled trial. J Arthroplasty. 2018;33(7):2153-8.

49. Abdel Shaheed C, Maher CG, Williams KA, McLachlan AJ. Interventions available over the counter and advice for acute low back pain: systematic review and meta-analysis. J Pain. 2014;15(1):2-15.

50. Anderson M, Perrin A. Tech adoption climbs among older adults. Washington: Pew Research Center: Internet, Science \& Technology; 2017;17:1-22.

51. Parker SJ, Jessel S, Richardson JE, Reid MC. Older adults are mobile too! Identifying the barriers and facilitators to older adults' use of mHealth for pain management. BMC Geriatr. 2013;13(1):43.

52. Agboola SO, Bates DW, Kvedar JC. Digital health and patient safety. JAMA. 2016;315(16):1697-8

53. Richardson BR, Truter P, Blumke R, Russell TG. Physiotherapy assessment and diagnosis of musculoskeletal disorders of the knee via telerehabilitation. J Telemed Telecare. 2017;23(1):88-95.

54. Cheok G, Tan D, Low A, Hewitt J. Is Nintendo Wii an effective intervention for individuals with stroke? A systematic review and meta-analysis. J Am Med Dir Assoc. 2015:16(11):923-32.

55. Howard IM, Kaufman MS. Telehealth applications for outpatients with neuromuscular or musculoskeletal disorders. Muscle Nerve. 2018;58(4):475-85.

\section{Publisher's Note}

Springer Nature remains neutral with regard to jurisdictional claims in published maps and institutional affiliations.

Ready to submit your research? Choose BMC and benefit from:

- fast, convenient online submission

- thorough peer review by experienced researchers in your field

- rapid publication on acceptance

- support for research data, including large and complex data types

- gold Open Access which fosters wider collaboration and increased citations

- maximum visibility for your research: over $100 \mathrm{M}$ website views per year

At BMC, research is always in progress.

Learn more biomedcentral.com/submissions 